\title{
A Short Primer on Collecting and Analyzing Energy R\&D Statistics
}

\section{JJ Dooley}

February 2000

Prepared for

U.S. Department of Energy

under Contract DE-AC06-76RLO 1830

Pacific Northwest National Laboratory

Operated for the U.S. Department of Energy

by Battelle Memorial Institute

Battelle 


\section{DISCLAIMER}

This report was prepared as an account of work sponsored by an agency of the United States Government. Neither the United States Government nor any agency thereof, nor Battelle Memorial Institute, nor any of their employees, makes any warranty, express or implied, or assumes any legal liability or responsibility for the accuracy, completeness, or usefulness of any information, apparatus, product, or process disclosed, or represents that its use would not infringe privately owned rights. Reference herein to any specific commercial product, process, or service by trade name, trademark, manufacturer, or otherwise does not necessarily constitute or imply its endorsement, recommendation, or favoring by the United States Government or any agency thereof, or Battelle Memorial Institute. The views and opinions of authors expressed herein do not necessarily state or reflect those of the United States Government or any agency thereof.

PACIFIC NORTHWEST NATIONAL LABORATORY operated by

BATTELLE MEMORIAL INSTITUTE for the

UNITED STATES DEPARTMENT OF ENERGY

under Contract DE-AC06-76RLO 1830 


\begin{abstract}
This report presents a short overview of various data sources available for understanding investment levels in energy research and development (R\&D). The report describes some of the strengths and weaknesses of these data sources. The report also discusses some issues that still need to be resolved in using energy R\&D statistics for decision-making purposes.
\end{abstract}

KEY WORDS: Energy R\&D statistics. 


\section{What is "energy R\&D"?}

We (the Global Climate Change Group at the Pacific Northwest National Laboratory) define energy research and development ("energy R\&D”) as the linked process by which an energy supply, energy end use, or carbon management technology moves from its conception in theory to its feasibility testing and small scale deployment. For the purposes of this paper, "energy R\&D" encompasses activities such as basic and applied research as well as technology development and demonstration in all aspects of production (e.g., mining, drilling, refining, exploration), power generation (i.e., nuclear fission and fusion, fossil, and renewable energy), transmission, distribution and energy storage and energy efficiency technologies. Carbon management technologies include but are not limited to advanced agro-forestry practices intended to enhance the absorptive capacity of soils and standing biomass to hold atmospheric carbon dioxide and engineered carbon capture (pre- and post-combustion) and engineered carbon capture and storage (e.g., in depleted gas and oil wells, coal-bed methane seams, deep saline reservoirs, and in the ocean).

This definition is based upon one contained in the President's Committee of Advisors on Science \& Technology (PCAST) Powerful Partnerships: The Federal Role in International Cooperation on Energy Innovation. Executive Office of the President. Government Printing Office.

Washington, DC. 1999.

It is important to stress that there is no universally accepted definition of energy $R \& D$. The definition above is one that we believe to be useful in guiding our research.

\section{Public Energy R\&D Data Sources}

There are two broad categories of sources for national public sector energy R\&D statistics. The first is aggregate statistics that are collected and reported by international organizations such as the International Energy Agency, the Organization for Economic Cooperation and Development and the United Nations. The second source of data is from country-sourced budget documents and national energy ministry program plans. Each of these sources has strengths and weaknesses for the analyst wishing to understand trends in energy R\&D.

- Data from international agencies - The primary benefit of data from organizations such as the IEA is that they are readily available in large, cross-sectional (more than 20 major industrialized countries), longitudinal (more than 20 years) data sets that represent energy R\&D expenditures of national governments. However, these data sets can be problematic. For example, often these data sets use market exchange rates, as opposed to purchasing power parities for their conversion to the common currency of US dollars. This method can introduce significant distortions into the data, distortions that can inflate the actual energy R\&D investments of countries (e.g., Japan). To compile these data sets, national governments are simply asked to fill out a survey instrument asking for instance, "how much did you spend on nuclear energy R\&D last year?" Although this yields a number that might be useful for understanding whether spending is going up or down, it reveals relatively little about the composition of this country's nuclear energy R\&D program. For example, has funding for fast breeder reactors been redirected to focus on geological disposition of radioactive wastes? Lastly, these data are collected without the use of a detailed taxonomy of what is meant by various categories and key terms (e.g., Does "R\&D" include deployment subsidies? Does "energy efficiency" include advances in fossil fuel combustion efficiency or does it only refer to end-use improvements?). This lack of a detailed taxonomy can lead to non-comparability across countries reporting what appear to be the same energy R\&D activities. 
- Data from country-specific sources -- Energy R\&D data sets that are built up through the collection and translation of country-specific data sources (e.g., budget documents, program plans) can solve many if not all of the problems outlined above. However, this is a very costly and time-consuming exercise that requires some level of sophistication in the collection and analysis phase.

\section{Private Energy R\&D Data Sources}

Data on private sector energy R\&D expenditures can be obtained from two broad classes of data sources. The first of these is government ministries that have some census/data collection mandate that extends to energy industries (e.g., the US Department of Energy and the Japanese Management and Coordination Agency, which is similar to the US Bureau of the Census). The second source is directly from the firms themselves or from interfirm collaborative enterprises such as the (US) Gas Research Institute. Each of these sources has strengths and weaknesses for the analyst wishing to understand trends in energy R\&D.

- Data from government ministries - A small number of the advanced industrialized nations known to support energy R\&D have government ministries that periodically survey private sector firms within their borders asking about energy R\&D investment levels (i.e., once again all that is being collected here is a monetary figure, not a narrative description of what precisely is being researched). Many of these surveys are artifacts of government's concern over the oil price shocks of a few decades ago. These data sets can be quite useful but they suffer many of the same problems as those noted above for international agencies; in particular, they suffer from problems associated with not using a detailed taxonomy when the collect their data. Analysts also need to pay particular attention to the assumptions used for assembling these data. For example, one of the US government data sources that describe private sector energy $R \& D$ investments assumes that firms do not subcontract energy R\&D activities to non- or not-for-profit institutes. In the United States, this is a significant error given the role played by entities such as the Electric Power Research Institute. Also, many of these government-compiled data sets do not survey the energy R\&D investments of small to medium-sized firms. This might result in an undercounting of energy R\&D investments in areas such as energy efficiency. Lastly, as is the case with any survey, these government data sets may suffer from high non-response rates.

- Data from individual firms or collaborative $R \& D$ enterprises - While clearly preferable to government surveys for the reasons cited above, collecting data from individual firms can be extremely time-consuming. Moreover, many firms consider this information to be proprietary and do not publish their energy R\&D investments. Lastly, many firms carry out research for other purposes (e.g., process improvement) that results in energy savings, but they do not categorize this as energy R\&D (this is discussed further in the next section). All of these factors can frustrate attempts to get an accurate picture of private sector energy $R \& D$ investments.

\section{Energy R\&D and R\&D that Affects Energy Use Are Not the Same}

All of the above sources of energy R\&D statistics, use the term energy R\&D in a conventional, possibly narrow sense of implying research activities that are explicitly carried out by governments or industry primarily to either increase energy supplies or to use energy more efficiently and cleanly. This then means that these data sets will exclude R\&D whose main and $a$ priori purpose was to create something like a new military system, even though at times strictly defined "military R\&D" has spilled over to benefit the energy industry. The most obvious example of this spillover phenomenon is combined cycle gas turbines, which have had a profound impact on the energy industry and are largely derivative of military jet engines. The exclusion of 
these ancillary R\&D efforts is driven by practicality and a desire to keep some temporal integrity to the data set being examined here. That is, only in an ex post facto sense can one identify these technologies that spill over into "energy R\&D" and the selection of these technologies is an inherently subjective exercise. It is more straightforward to track those R\&D expenditures that at the time of their conception were believed to be needed because of their relevance to energy.

\section{Funds Spent on Energy R\&D is an Input Measure}

Analysts who collect energy R\&D expenditure data typically use these data as a proxy measure for some public or private good, e.g., are we making progress in developing technologies to address climate change or to maintain national "energy security"? Energy R\&D expenditures are one of many possible input measures that contribute to the attainment of goals such as these. They are used as proxy measures because energy R\&D statistics are somewhat easy to collect and have the appearance of being easy to interpret. In contrast, output measures such as "energy intensity (energy input per unit of gross domestic product) are notoriously difficult to interpret (e.g., is the improvement in energy intensity due to the introduction of more fuel efficient automobiles or to warmer winters or to structural changes in the economy?) Researchers continue to work on devising a defensible mapping of energy R\&D inputs to some meaningful output measure. Until they succeed, analysts will continue to use energy R\&D expenditures as an imperfect proxy for these output measures.

\section{Can We Measure Energy R\&D Productivity?}

Most recent studies of trends in energy R\&D have documented significant reductions in the level of support for these investments and a shift towards supporting less risky, more immediate payoff research. Many analysts have interpreted these data as a dangerous impediment that will delay or prevent the attainment of many energy policy goals.

On the other hand, some analysts (often senior members of energy firms) claim that a reduction in the amount spent on energy R\&D might not be bad if energy R\&D-producing laboratories have become more efficient in their delivery of energy R\&D results. Another reason offered along these lines is that firms are increasingly turning to collaborative R\&D mechanisms to carry out research and therefore many firms do not need to invest in duplicative research (i.e., even though less is being invested in the aggregate, more is being purchased through collaboration). While there is no data to support or refute "the increases in energy R\&D efficiency" hypothesis, there is some indication that in certain areas of energy research firms are actually turning away from collaborative research mechanisms while in other aspects of energy R\&D collaboration appears to be a viable mechanism.

These diverging views are in large measure related to the above discussion of input and output measures. There are no definitive studies that demonstrate which of these two competing theories is correct or the extent to which one or the other is a better representation of reality.

\section{Policy Statements and Energy R\&D Investments Are not Strictly Correlated}

Analysts attempting to understand trends in energy R\&D should not place too much faith in government or private sector policy statements about the state of their energy R\&D investments. For example, many governments have spent most of the 1990s talking about redirecting their energy R\&D portfolios to focus on climate change or to put more emphasis on renewable energy R\&D. The budgets that describe how these governments have actually allocated their energy R\&D funds reveal a modest change in emphasis, however. 


\section{Recent Literature on Underinvestment in Energy R\&D}

Over the past few years there has been a resurgence of interest in understanding trends in energy $\mathrm{R} \& \mathrm{D}$ and the determinants and drivers of investment levels in energy R\&D. Most of this interest can be traced to concerns over whether the industrialized nations are investing sufficiently in energy $R \& D$ to address the (possible) threat posed by climate change. The following is an admittedly incomplete list of some of this literature. In consulting this literature, it is important to consider the source of the data used in the analysis of energy R\&D trends for the reasons listed above.

JJ Dooley and PJ Runci. Adopting A Long View to Energy R\&D and Global Climate Change. A commissioned paper for the President's Council of Advisors on Science and Technology's study "Powerful Partnerships: The Federal Role in International Cooperation on Energy Innovation.” PNNL-12115. Washington, D.C. February 1999.

JJ Dooley, PJ Runci, EEM Luiten. Energy R\&D in the Industrialized World: Retrenchment and Refocusing. PNNL-12061. Washington, D.C. December 1998.

JJ Dooley. "Unintended Consequences: Energy R\&D in Deregulated Market." Energy Policy. pp. 547-555. June 1998.

JJ Dooley. US National Investments in Energy R\&D: 1974-1996. Pacific Northwest National Laboratory. PNNL-11788. Washington, D.C. December 1997. This research was request by the White House Council of Economic Advisors and is published in the Economic Report of the President: 1998. Council of Economic Advisors. Washington, D.C. February 1998.

JA Edmonds, JJ Dooley, SH Kim. "Long-term Energy Technology Needs and Opportunities for Stabilizing Atmospheric $\mathrm{CO}_{2}$ Concentrations." Printed in Climate Change Policy: Practical Strategies to Promote Economic Growth and Environmental Quality, a Monograph Series on Tax, Trade, and Environmental Policies and Economic Growth from the American Council for Capital Formation. Washington, D.C., May 1999.

General Accounting Office (GAO) Changes in Electricity-Related R\&D Funding, GAO-RCED96-203, (Washington, DC: United States Government Printing Office, 1996).

M.I. Hoffert, Calderia, K., Jain, A.K., Haites, E.F., Harvey, L.D., Potter, S.D., Schlesinger, M.E., Schneider, S.H., Watts, R.G., Wigley, T.M.L., Wuebbles, D.J. 1998. "Energy Implications of Future Stabilization of Atmospheric $\mathrm{CO}_{2}$ Content." Nature. Vol 35, Issue 29. Pp. 881-884.

John Holdren et al. (1999) President's Committee of Advisors on Science \& Technology (PCAST) "Powerful Partnerships: The Federal Role in International Cooperation on Energy Innovation." Executive Office of the President. Government Printing Office. Washington, DC. 1999.

John Holdren et al. (1997). Federal Energy Research and Development for the Challenges of the Twenty-first Century. Report of the Energy Research and Development Panel of the President's Committee of Advisors on Science and Technology. Washington, DC.

Robert M. Margolis and Daniel M. Kammen. "Underinvestment: The Energy Technology and R\&D Policy Challenge.” Science 1999 July 30; 285: 690-692. 